\title{
High-Sensitivity Troponin T and NT-proBNP Kinetics in Breast Cancer Chemotherapy
}

\author{
Pooja Advani ${ }^{a}$ Jonathan Hoyne ${ }^{b}$ Alvaro Moreno-Aspita ${ }^{a}$ Marcia Dubin ${ }^{c}$ \\ Shelly Brock ${ }^{a}$ Caroline Harlow $^{b}$ Saranya Chumsri ${ }^{a}$ Thomas Suter $^{d}$ \\ Joseph L. Blacksheare \\ ${ }^{\mathrm{a}}$ Division of Hematology-Oncology, and Departments of ${ }^{\mathrm{b}}$ Laboratory Medicine and Pathology, ${ }^{\mathrm{C}}$ Clinical Research \\ and ${ }^{\mathrm{d} C a r d i o l o g y}$, Berne University Hospital, Bern, Switzerland; e Department of Cardiovascular Diseases, Mayo Clinic, \\ Jacksonville, FL, USA
}

\section{Keywords}

Echocardiography $\cdot$ Breast cancer · High-sensitivity troponin T · Brain natriuretic peptide - Trastuzumab . Doxorubicin

\begin{abstract}
Background/Aims: Doxorubicin (DOX) and trastuzumab (TRA) are associated with cardiac dysfunction. Method: High-sensitivity troponin $\mathrm{T}$ (hs- $\mathrm{TnT}$ ) and brain natriuretic peptide attached to the amino acid $\mathrm{N}$-terminal fragment in the prohormone (NT-proBNP) were measured before and on days $+1,+2,+3$, and +7 during cycles 1 and 2 of therapy with DOX or TRA in breast cancer patients. Results: Five of eleven DOX-treated women, compared with 2/11 TRA-treated women, had undetectable baseline hs-TnT. By day +1 of cycle 2 , all the DOX-treated women ( $p=0.03$ ) but only $7 / 11$ TRA-treated women ( $p=\mathrm{ns}$ ) had detectible hs-TnT. Time to peak was 1-2 days for both groups. In the DOX-treated women, hs-TnT showed significant peaks from precycle baseline, increases in precycle 1 to precycle 2 levels, and a cycle 1 to
\end{abstract}

Clinical trial NCT No. NCT01771549

\section{KARGER}

(C) 2017 S. Karger AG, Basel

E-Mail karger@karger.com

www.karger.com/che cycle 2 peak and area under the curve (AUC). hs-TnT increased from precycle $(1,4.6 \pm 6.3 \mathrm{pg} / \mathrm{mL})$ to a cycle 2 peak of $16.1 \pm 15.0 \mathrm{pg} / \mathrm{mL}(p<0.002)$. No increases were seen with the TRA treatment. Transient posttreatment increases in NTproBNP were seen after both therapies. Conclusion: DOX was associated with increased pretreatment baseline, peak, and AUC hs-TnT levels. Both DOX and TRA acutely perturb NT-proBNP. Assessment of pre- and posttreatment hs-TnT could be a means of quantifying cumulative myocardial injury in the course of chemotherapy. @ 2017 S. Karger AG, Basel

\section{Introduction}

Doxorubicin (DOX) and trastuzumab (TRA) are widely used in the treatment of breast cancer and are associated with the development of cardiac dysfunction. There is a need to identify patients who are at a high risk of developing cardiac complications from these agents, and monitoring during treatment could allow modifications designed to minimize cardiac dysfunction [1, 2]. Current monitoring, with ejection fraction (EF), lacks the

Joseph L. Blackshear

Mayo Clinic Florida

4500 San Pablo Road

Jacksonville, FL 32224 (USA)

E-Mail blackshear.joseph@ @ayo.edu 
Table 1. Baseline characteristics of patients in the doxorubicin group

\begin{tabular}{|c|c|c|c|c|c|c|c|c|}
\hline $\begin{array}{l}\text { Patient } \\
\text { No. }\end{array}$ & $\begin{array}{l}\text { Age, } \\
\text { years }\end{array}$ & $\begin{array}{l}\text { Breast } \\
\text { cancer stage }\end{array}$ & $\begin{array}{l}\text { ER/PR/HER2 sta- } \\
\text { tus of tumor }\end{array}$ & $\begin{array}{l}\text { Adjuvant } \\
\text { radiation/side }\end{array}$ & $\begin{array}{l}\text { LVEF at } \\
\text { baseline, \% }\end{array}$ & $\begin{array}{l}\text { LVEF at } 3 / 6 / 9 / 12 \\
\text { months, } \%\end{array}$ & $\begin{array}{l}\text { Total DOX } \\
\text { doses, } n\end{array}$ & $\begin{array}{l}\text { Development } \\
\text { of CHF }\end{array}$ \\
\hline 1 & 50 & III & $+/+/-$ & yes/left & 60 & $-/-/ 65 /-$ & 4 & no \\
\hline 2 & 48 & II & $-1-1-$ & yes/left & 61 & $-1-1-1-1$ & 4 & no \\
\hline 3 & 47 & II & $+1+1-$ & no & 57 & $47 / 53 /-/ 51$ & 4 & yes \\
\hline $4^{\mathrm{a}}$ & 48 & II & $+/+/+$ & yes/right & 56 & $56 / 53 / 52 / 50$ & 4 & no \\
\hline 5 & 71 & II & $+1-1-$ & yes/left & 65 & $-1-1-1-$ & 4 & no \\
\hline 6 & 43 & III & $+/+/-$ & yes/right & 68 & $56 /-1-1-$ & 4 & no \\
\hline 7 & 50 & II & $+/+1-$ & yes/left & 62 & $-1-1-1-$ & 4 & no \\
\hline 8 & 59 & III & $+1+1-$ & yes & 67 & $-1-1-1-$ & 4 & no \\
\hline 9 & 52 & II & $-1-1-$ & yes & 64 & $63 /-1-1-$ & 4 & no \\
\hline 10 & 58 & III & $-1-1+$ & yes/right & 57 & $60 / 58 / 56 / 60$ & 4 & no \\
\hline 11 & 63 & II & $+1+1-$ & yes/left & 63 & $67 /-/ 60 /-$ & 4 & no \\
\hline
\end{tabular}

DOX, doxorubicin; LVEF, left ventricular ejection fraction; ER, estrogen receptor; PR, progesterone receptor; HER2, human epidermal receptor2; CHF, congestive heart failure.

a This patient had previously received 25 doses of trastuzumab.

sensitivity to detect early subclinical changes or predict subsequent declines in function with treatment [2]. Cardiac biomarkers such as troponins, brain natriuretic peptide attached to the amino acid $\mathrm{N}$-terminal fragment in the prohormone (NT-proBNP), and myeloperoxidase have been explored as potential means of early identification of chemotherapy-induced cardiac toxicity in vulnerable patients [3-5]. The conventional troponin $\mathrm{T}(\mathrm{TnT})$ assay performs well for discriminating noncardiac chest pain from myocardial infarction, but its imprecision at low values makes the detection of subclinical myocardial damage unreliable. High-sensitivity (hs)-TnT assays overcome this limitation. However, the kinetics early after chemotherapy remain undefined [6, 7]. A new hs-TnT assay (Roche Diagnostics, Indianapolis, IN, USA) had a detection limit of $3 \mathrm{pg} / \mathrm{mL}$ pre-US FDA approval during testing. The post-US FDA approval detection limit is 6 $\mathrm{pg} / \mathrm{mL}$, and 99 th percentile threshold for women is $14 \mathrm{pg} /$ $\mathrm{mL}$. The objective of our pilot study was to evaluate the kinetics of hs-TnT in comparison to a widely used biomarker, NT-proBNP, during the first and second cycles of treatment with DOX or TRA in breast cancer patients.

\section{Methods}

We studied hs-TnT and NT-proBNP levels just before (at baseline), and on days $+1,+2,+3$, and +7 during the first and second cycles in women with stage I-III breast cancer treated with adjuvant or neoadjuvant DOX (administered as dose-dense) or TRA.
Cardiac imaging was performed as per usual clinical care, usually prior to treatment, and then either at 3,6 , or 12 months. The characteristics of hs-TnT differ from the conventional assay [8]. In this protocol, blood was collected in serum tubes, centrifuged, and stored frozen at $-80^{\circ} \mathrm{C}$. Each sample had a single freeze/thaw cycle. All laboratory analyses were conducted blinded to clinical status. NT-proBNP (detection limit: $5 \mathrm{pg} / \mathrm{mL}$ ) was performed on a Cobas e601 automated immunoassay analyzer using the Elecsys proBNP II assay. hs-TnT measurement was performed on a Cobas E601 automated immunoassay analyzer using the Elecsys TnT hs assay (Roche Diagnostics). This assay as tested had a limit of detection of $3 \mathrm{pg} / \mathrm{mL}$, and the 99th percentile cutoff in a healthy population is $14 \mathrm{pg} / \mathrm{mL}$. Mean and standard deviation are presented. Calculated kinetic variables included baseline and peak values, time to peak, and baseline-corrected area under the curve (AUC). In calculating the AUC, missing values for DOX (7/55 samples) and TRA (1/55 samples), were imputed from the last known value, and values below the hs-TnT detection limit, were assigned a value of $2 \mathrm{pg} / \mathrm{mL}$. The pretreatment to posttreatment continuous variables were analyzed statistically by the $t$ test. Nonparametric comparisons were assessed with the Fisher exact test. $p<0.05$ was considered the threshold for statistical significance.

\section{Results}

Median ages were 51 years (DOX group, $n=11$; Table 1 ) and 60 years (TRA, $n=11$; Table 2) years. Left ventricular EF was normal at baseline in women treated with DOX $(63 \pm 4 \%)$ and TRA $(64 \pm 4 \%)$. Four women in the TRA group had received DOX prior to study enrollment. One woman in the TRA group received concurrent

Chemotherapy 2017;62:334-338 DOI: $10.1159 / 000477797$ 
Table 2. Baseline characteristics of patients in the trastuzumab group

\begin{tabular}{|c|c|c|c|c|c|c|c|c|}
\hline $\begin{array}{l}\text { Patient } \\
\text { No. }\end{array}$ & $\begin{array}{l}\text { Age, } \\
\text { years }\end{array}$ & $\begin{array}{l}\text { Breast } \\
\text { cancer stage }\end{array}$ & $\begin{array}{l}\text { ER/PR/HER2 } \\
\text { status of tumor }\end{array}$ & $\begin{array}{l}\text { Adjuvant } \\
\text { radiation/side }\end{array}$ & $\begin{array}{l}\text { LVEF at } \\
\text { baseline, \% }\end{array}$ & $\begin{array}{l}\text { LVEF at } 3 / 6 / 9 / 12 \\
\text { months, } \%\end{array}$ & $\begin{array}{l}\text { Total TRA } \\
\text { doses, } n\end{array}$ & $\begin{array}{l}\text { Development } \\
\text { of } \mathrm{CHF}\end{array}$ \\
\hline 1 & 80 & I & $+/-1+$ & yes/right & 57 & $55 / 63 / 63 / 56$ & 25 & no \\
\hline 2 & 64 & III & $-1-1+$ & yes/right & 55 & $66 / 62 / 60 / 67$ & $25^{\mathrm{a}}$ & no \\
\hline 3 & 64 & I & $+1+1+$ & Yes/right & 62 & $62 / 63 / 60 / 64$ & $19^{\mathrm{b}}$ & no \\
\hline 4 & 41 & III & $+1-1+$ & yes/right & 67 & $74 / 58 / 63 / 62$ & $25^{\mathrm{a}}$ & no \\
\hline 5 & 75 & III & $-1-1+$ & yes/right & 56 & $55 / 59$ & $25^{\mathrm{a}}$ & no \\
\hline 6 & 79 & I & $+/+1+$ & yes/right & 66 & $61 / 62 / 68 / 67$ & 25 & no \\
\hline 7 & 64 & III & $-1-1+$ & yes/left & 66 & $63 / 65 / 61 / 69$ & $25^{\mathrm{a}}$ & no \\
\hline 8 & 61 & III & $+/-1+$ & yes/right & 67 & $64 / 56 / 63 / 63$ & 25 & no \\
\hline 9 & 45 & II & $+/+1+$ & no & 69 & $-/ 67 / 72$ & 25 & no \\
\hline 10 & 54 & I & $-1-1+$ & no & 64 & $-/ 65 / 73$ & 25 & no \\
\hline 11 & 48 & I & $-/+1+$ & yes/left & 64 & $-/ 64 / 65$ & 25 & no \\
\hline
\end{tabular}

TRA, trastuzumab; LVEF, left ventricular ejection fraction; ER, estrogen receptor; PR, progesterone receptor; HER2, human epidermal receptor 2; CHF, congestive heart failure.

${ }^{a}$ Patients also previously received doxorubicin. ${ }^{\mathrm{b}} \mathrm{TCH}$ (taxotere, carboplatin, herceptin) chemotherapy.

Table 3. Mean values of hs-TnT and NT-proBNP for doxorubicin and trastuzumab

\begin{tabular}{|c|c|c|c|c|c|c|}
\hline & DOX, cycle 1 & DOX, cycle 2 & $p$ value & TRA, cycle 1 & TRA cycle 2 & $p$ value \\
\hline \multicolumn{7}{|l|}{ hs-TnT } \\
\hline At baseline, $\mathrm{ng} / \mathrm{mL}$ & 4.6 & 9.3 & $<0.002$ & 7.7 & 5.0 & ns \\
\hline Peak, ng/mL & $9.6^{* *}$ & $16.1^{\dagger}$ & $<0.002$ & 8.0 & 6.8 & ns \\
\hline Time to peak, days & 1.6 & 1.5 & ns & 1.1 & 1.3 & ns \\
\hline AUC above baseline & $7.1 \pm 13.4$ & $27 \pm 19$ & $<0.001$ & $-1.4 \pm 7.2$ & $-5 \pm 17$ & ns \\
\hline \multicolumn{7}{|l|}{ NT-proBNP } \\
\hline At baseline, $\mathrm{pg} / \mathrm{mL}$ & 94 & 90 & ns & 124 & 80 & ns \\
\hline Peak, pg/mL & $361^{*}$ & $359^{*}$ & ns & 209 & $206^{\dagger}$ & ns \\
\hline Time to peak, days & 1.8 & 1.9 & ns & 2.2 & 1.8 & ns \\
\hline AUC above baseline & 423 & 499 & ns & $78^{* *}$ & $-32^{* *}$ & $<0.5$ \\
\hline
\end{tabular}

DOX, doxorubicin; TRA, trastuzumab. ${ }^{*} p<0.001 ;{ }^{\dagger} p \leq 0.01 ; * * p<0.03 ;{ }^{\dagger \dagger} p=0.002 ; \mathrm{ns}, p>0.05$.

docetaxel and carboplatin. Their data were included in the assessment of the acute, short-term response to TRA. Baseline hs-TnT was undetectable in 5/11 DOX-treated women and in 2/11 TRA-treated women. By cycle 2, day +1 , there was a detectable level of hs-TnT in all the DOXtreated women $(p=0.03)$ but only in 7/11 TRA-treated women ( $p=n s)$. Three of the four TRA-treated women with prior anthracycline exposure had the highest baseline and posttreatment hs-TnT values, while the fourth patient had no detectable level (Fig. 1). The sole patient to develop cardiac dysfunction (Table 1, patient 3) had the highest values of hs-TnT. Individual results for all patients are shown in Figure 1.
In DOX-treated women, hs-TnT increased significantly from precycle 1 to the peak of cycle $1(4.6 \pm 6.3$ to $9.6 \pm 12.0 \mathrm{pg} / \mathrm{mL} ; p<0.03)$, and from precycle 2 to the peak of cycle $2(9.3 \pm 9.2$ to $16.1 \pm 15 \mathrm{pg} / \mathrm{mL} ; p<0.005)$ (Table 3; Fig. 1). Cycle 1 baseline to cycle 2 baseline increases were significant $(p=0.004)$, as were the cycle 1 peak to the cycle 2 peak $(p=0.002)$. Day 7 posttreatment levels were not significantly different from baseline values, either for cycle $1(6.5 \pm 10.2 \mathrm{pg} / \mathrm{mL})$ or cycle $2(10.3$ $\pm 9.8 \mathrm{pg} / \mathrm{mL}$ ). A positive AUC of 7.1 \pm 13.4 was noted for cycle 1 , and the AUC increased significantly to $27 \pm 19$ $(p<0.001)$ in cycle 2. One woman in the DOX group developed cardiac dysfunction 3 months after the com- 


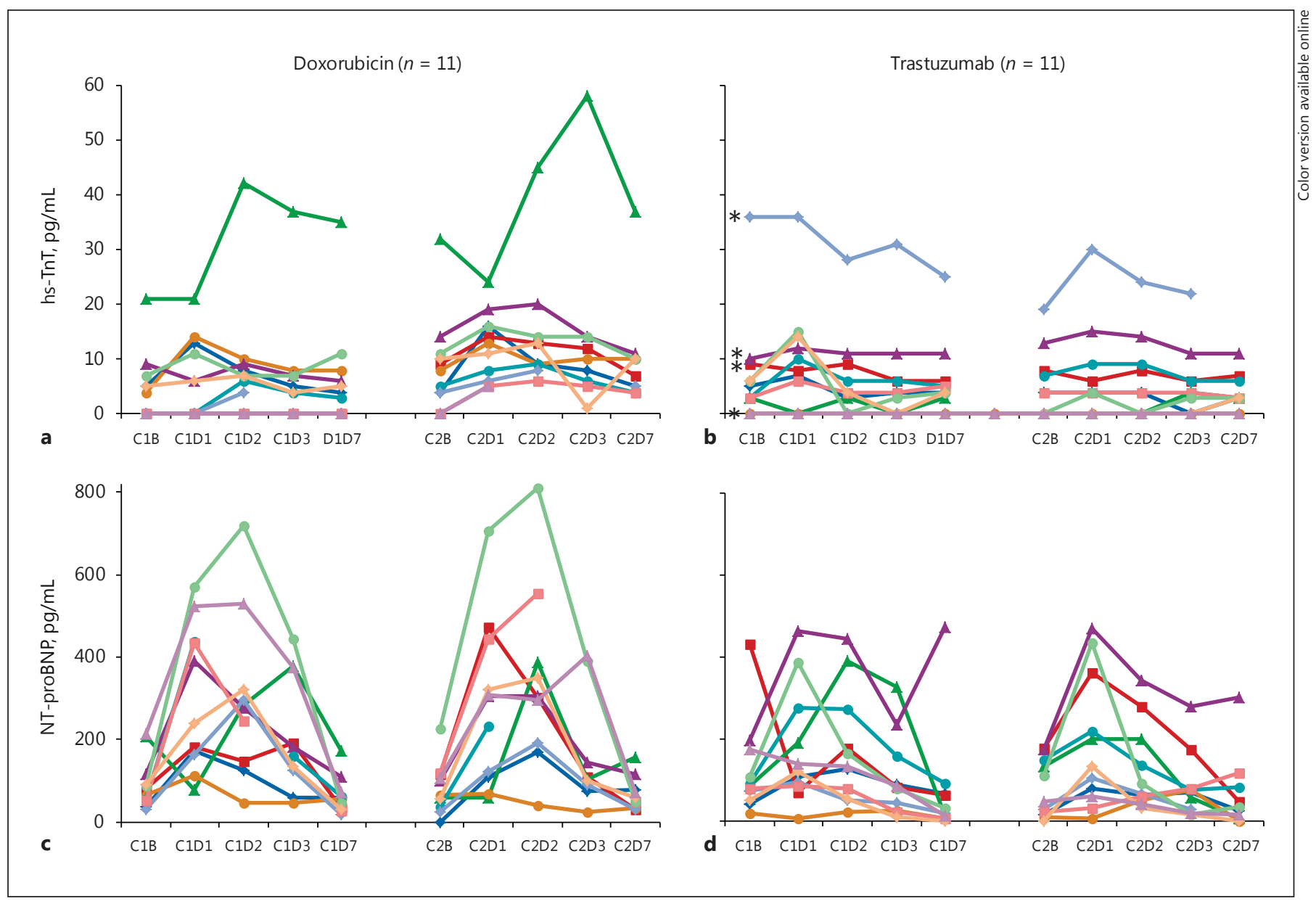

Fig. 1. Individual patient data for high-sensitivity troponin $\mathrm{T}(\mathbf{a}, \mathbf{b})$ and NT-proBNP $(\mathbf{c}, \mathbf{d})$ in women treated with doxorubicin or trastuzumab. The asterisk indicates trastuzumab-treated women with prior anthracycline exposure. Individual values of cardiac biomarkers. C1B, cycle 1, baseline; C1D1, cycle1, day 1, etc.

pletion of treatment, with a fall in EF from precycle 1 of 57 to $47 \%$. She had the highest posttreatment value of hs- $\operatorname{TnT}(58 \mathrm{pg} / \mathrm{mL})$ recorded during cycle 2 . No significant increases in hs-TnT were seen in the TRA-treated women.

Highly significant transient increases in NT-proBNP were noted after DOX treatment, from precycle 1 to the cycle 1 peak ( $82 \pm 50$ to $363 \pm 173 \mathrm{pg} / \mathrm{mL} ; p<0.001)$ and from precycle 2 to the cycle 2 peak ( $90 \pm 58$ to $371 \pm 213$ $\mathrm{pg} / \mathrm{mL} ; p<0.001)$. AUC was positive for both cycles 1 and 2 , but similar without an increase from cycle 1 to cycle 2 ( $427 \pm 321$ vs. $471 \pm 323 \mathrm{pg} / \mathrm{mL}$; ns). In the TRA-treated women, a significant increase in NT-proBNP was noted only from cycle 2 baseline to the cycle 2 peak ( $80 \pm 71$ to $206 \pm 150 \mathrm{pg} / \mathrm{mL} ; p<0.002$ ).

hs-TnT in Breast Cancer

\section{Discussion}

In patients with myocardial infarction, cardiac troponin peaks approximately $12 \mathrm{~h}$ after symptom onset [8]. However, oncologic troponin research has focused on sampling distant from the administration of potentially toxic drugs, and the optimal timing for sampling is unknown. Conventional troponin assays have not yielded a reliably quantifiable early signal of troponin elevation in large percentages of patients $[9,10]$ and, at any rate, the assay precision is poor at low concentrations [5]. Cardinale et al. [3], using conventional troponin I (TnI) for samples early after treatment, found abnormal elevations in 65/204 (32\%) of the patients receiving high-dose chemotherapy at some point, with higher percentages later in the course of treatment. All patients had normal values

Chemotherapy 2017;62:334-338 DOI: $10.1159 / 000477797$ 
at baseline, and abnormal levels were observed in 112/661 cycles. In the 65 patients who demonstrated elevated TnI, over half of the elevations were detected immediately after infusion.

Thus far, hs assays, which have improved precision at very low concentrations, have been evaluated at 3 and 6 months after treatment. Sawaya et al. [11] measured increases in ultrasensitive TnI (from 1.3 to $23 \mathrm{pg} / \mathrm{mL}$ ), with the highest levels occurring at the end of therapy. Moreno et al. [12] noted increments of ultrasensitive TnI after anthracycline in $57 \%$ of patients. After cycle 3 (21-day cycles) and the completion of 8 cycles of R-CHOP including epirubicin for non-Hodgkin's lymphoma, Kang et al. [13] noted a significant increase in hs-TnT from 1 to 7.3 $\mathrm{pg} / \mathrm{mL}$.

Our data suggest that there is an early hs-TnT signal after DOX treatment, which may provide a means of quantifying myocardial damage during the initial cycles of chemotherapy in a manner that could identify patients at risk, and could allow for early pre-emptive cardioprotective medical intervention, treatment modification, or the need for posttreatment cardiac monitoring. Increases in precycle to cycle levels, in peak to peak levels, and in AUC from cycle 1 to cycle 2 suggest that myocardial damage increases with successive doses. Our pilot study was limited by a small sample size, which prevented us from identifying a threshold value after cycles 1 or 2 which could provide confidence limit-based estimates of future risk of cardiac dysfunction. The results of similar testing in cycles 3 and 4 for DOX, and, indeed, in cycles 3-25 for TRA are unknown. Other agents given with DOX may also have influenced the results. Missing data from the kinetic analysis, requiring imputation, reduces the confidence of kinetic data.

In conclusion, cycles 1 and 2 of DOX are associated with an early rise in hs-TnT in breast cancer chemotherapy, with increases in the kinetic parameters of troponin release in cycle 2 compared to cycle 1.

\section{Acknowledgements}

We thank Roche Diagnostic Corp., Indianapolis, IN, USA, for providing reagent kits for the assays. We also thank Tammy Wollett for her expertise in validating assays and running the clinical samples.

\section{Disclosure Statement}

None of the authors report a conflict of interest.

\section{References}

1 Menna P, Salvatorelli E: Primary prevention strategies for anthracycline cardiotoxicity: a brief overview. Chemotherapy 2017;62:159168.

2 Jensen BV, Skovsgaard T, Nielsen SL: Functional monitoring of anthracycline cardiotoxicity: a prospective, blinded, long-term observational study of outcome in 120 patients. Ann Onc 2002;13:699-709.

3 Cardinale D, Sandri MT, Martinoni A, Tricca A, Givelli M, Lamantia G, Cinieri S, Martinelli G, Cipolla C, Fiorentini C: Left ventricular dysfunction predicted by early troponin I release after high dose chemotherapy. J Am Coll Cardiol 2000;36:517-522.

4 Ky B, Putt M, Sawaya H, French B, Januzzi JL, Sebag IA, Plana JC, Cohen V, Banchs J, Carver JR, Wieger SE, Martin RP, Picard M, Gerszten RE, Alpern EF, Passeri J, Kuter I, ScherrerCrosbie M: Early increases in multiple biomarkers predict subsequent cardiotoxicity on patients with breast cancer treated with doxorubicin, taxanes, and trastuzumab. J Am Coll Cardiol 2014;63:809-816.

5 Romano S, Fratini S, Ricevuto E, Procaccini V, Stifano G, Mancini M, Di Mauro M, Ficorella C, Penco M: Serial measurements of
NT-proBNP are predictive of non-high dose anthracycline cardiotoxicity in breast cancer patients. Brit J Cancer 2011;105:1663-1668.

6 Salvatici M, Cardinale D, Botteri E, Bagnardi V, Mauro C, Casatella MC, Lentati P, Bottari F, Zorzino L, Passerini R, Cipolla CM, Sandri MT: TNI-ultra assay measurments in cancer patients: comparison with the conventional assay and clinical implications. Scand J Clin Lab Invest 2014;74:385-391.

7 Clark SJ, Pippon M, Hemsworth S, Newland P, Pizer B: Cardiac troponin T following anthracycline chemotherapy in children and adolescents. J Chemotherapy 2007;19;332334.

8 Mueller M, Biener M, Vafaie M: Absolute and relative kinetic changes of high-sensitivity cardiac troponin $\mathrm{T}$ in acute coronary syndrome and in patients with increased troponin in the absence of acute coronary syndrome. Clin Chem 2012;58:209-218.

9 Auner HW, Tinchon C, Linkesch W, Tiran A, Quehenberger F, Link H, Sill H: Prolonged monitoring of troponin $\mathrm{T}$ for the detection of anthracycline cardiotoxicity in adults with hematological malignancies. Ann Hematol 2003;82:218-222.
10 Chow LWC, Loo WTY, yip AYS, Ng ELY: Acceptable cardiac safety profile of neoaduvean 5-flourouracil, epirubicin, cyclophosphamide and celecoxib (FEC_C) for breast cancer: a subanalysis of biomarkers for cardiac injury. Int J Biol Markers 2013;28:E92-E99.

11 Sawaya H, Sebag IA, Plana JC, Januzzi JL, Ky B, Tan TC, Cohen V, Banchs J, Carver JR, Wiegers SE, Martin RP, Picard MH, Gerszten RE, Halpern EF, Passeri J, Kuter I, ScherrerCrosbie M: Early detection and prediction of cardiotoxicity in chemotherapy-treated patients. Am J Cardiol 2011;107:1375-1380.

12 Moreno R, Costa R, Mazar RC, Silva MB, de Souza MG, Murad N, Feder D, Azzalis LA, Alves BC, Gehrke FS, Adami F, Fonseca FL: Evaluation of ultrasensitive cardiac troponin I levels in patient with breast cancer during chemotherapy. Clin Chim Acta 2014;427: 70-71.

13 Kang Y, Xu X, Cheng L, Li L, Sun M, Chen H, Pan C, Shu X: Two-dimensional speckletracking echocardiography combined with high-sensitivity troponin $\mathrm{T}$ in early detection and prediction of cardiotoxicity during epirubicine-based chemotherapy. Eur J Heart Failure 2014;16:300-308. 